1 Moore K, Thompson C, Hayes R. Diabetes and extreme altitude mountaineering. Br $\mathcal{F}$ Sports Med 2001;35:83.

2 Panofsky D. IDEA 2000 Expedition Summary. January 2001. http:॥www.idea2000.org.

Sports doctors' resuscitation skills under examination-additional facts

EDITOR,-Further to the recent article Sports doctors' resuscitation skills under examination: do they take it seriously?", ${ }^{1}$ there are some additional facts that support the argument.

The University of Bath diploma course in sports medicine for doctors includes teaching material on life support and spinal management. The relevant section of the primary care module workbook, edited by Lavis and Rose, contains a full description of resuscitation and spinal management. The tutor marked assignments that indicate the completion of the primary care module require description of the application of these skills to a defined situation. The residential component of the course, designed to rehearse practical skills, includes three hours of first aid revision and training conducted by one or more of the article authors.

The failure rate in the examination of proficiency in basic life support and spinal management of a potential spinal injury is in marked contrast with that of the other components of the course where a reasonable pass rate is obtained.

It does therefore seem possible that the reported failure rate is not due to the inadequacy of the teaching material, rather a perception by doctors that resuscitation and life support is not relevant to their work. The article reports other studies that highlight the poor standards of doctors in these skills. It cannot be assumed that doctors entering a sports medicine teaching course have previously acquired proficiency in the skills of resuscitation and the management of potential spinal injury.

It does suggest that there is an urgent need to educate doctors in their responsibility, not only to the community as a whole but also to the at higher risk sporting population, to be proficient in life saving skills. The widely reported court case in which the boxer Michael Watson successfully claimed damages for personal injuries sustained in a professional boxing contest-he sustained a brain haemorrhage and permanent injurydrew the comment from the judge that he had heard nothing to suggest that the doctors at the ringside were chosen because of their specialised knowledge. ${ }^{2}$

A requirement for an annual practical appraisal of the lifesaving skills of doctors involved in the everyday care of patients may not be inappropriate.

M B BOTTOMLEY Tutor and former Director of Studie Sports Medicine for Doctors University of Bath Bath, UK

1 Lavis M, Rose J, Jenkinson T. Sports doctors' resuscitation skills under examination: do they take it seriously?” Br $\mathcal{F}$ Sports Med 2001;35: $128-130$.

2 Mr Justice Ian Kennedy. Michael Watson v The British Boxing Board of Control [1999] $94 \mathrm{~W}$ 1081 .
The future for the field of sports medicine

EDIToR,-Can I begin by expressing my appreciation for the introductory free access to the journal since its launch on the web earlier this year.

This year I have undertaken an intercalated degree in clinical medicine which has been offered by the Department of Medicine and Therapeutics at Glasgow University for the past four years. Over 60 of my fellow students opted to do the same. We each, however, opt to do a specialist module in addition to a common core course. The options include cardiovascular studies, clinical neuroscience, and cancer studies, among others. I chose to do sports medicine, largely because of my own interest and participation in sport. Indeed participation in sport was a common factor among the 10 students opting for this module.

Admittedly many of us felt that this, compared with some of the other modules, would not be a particularly taxing option. Our reputation as "slackers" among the rest of the year group was evident. As far as they were concerned, we were lectured in fun things while they grappled with the serious issues at the cutting edge of medical research! However, although I have thoroughly enjoyed the lectures, this was by no means the easy option, and I agree wholeheartedly with Paul McCrory that it is about time attitudes changed.

Who says there are no serious issues in this field? Consider the dilemma of the physician who has been pleaded with to give a pain killing injection to a young player, with the risk of more serious damage, because an international scout will be at this match and this may be his only chance to make an impression. Consider also the responsibility, swift judgment, and strength of character required when faced with the head injured player who knows he will be out for a whole season if he comes off, and then of course there's his coach . .

The elite athlete has emerged as someone with specialist medical needs, and we need specialist sports medicine physicians to respond.

But then the field of sports medicine goes far beyond these more traditional roles into a wide range of other specialties: cardiology, respiratory medicine, gynaecology, rheumatology, neurology, to name but a few of the areas our lecturers have explored. We need specialists who can advise in each of these areas, but to enable them to do so we need to provide them with the necessary evidence base.

What has been most evident throughout is the requirement for more well conducted research and clinical guidelines based in this field. We are a generation of medical students for whom the term evidence based medicine (EBM) is used as commonly as coronary heart disease (CHD). My fellow students this year are involved in researching areas as diverse as the thrombolytic response and contrasting platelet activity during exercise (surprisingly there are still no definitive answers here), the role of strength training in rheumatoid arthritis, the relation between knee injuries in female footballers and the menstrual cycle, the barriers to exercise in cardiac rehabilitation patients, to name but a few.

I may only be at the beginning of my medical career but I feel I have had a valuable insight into the challenge and diversity presented by this field and the great potential it holds, and I look forward to changed attitudes and a more formal recognition of this specialty.

C MARTIN

77 Schaw Drive, Bearsden

Glasgow G61 3AT, Scotland, UK

\section{Height of Kilimanjaro}

EdITOR,-As one who, for my running exploits on Kilimanjaro, was mentioned in Damian Bailey's ${ }^{1}$ excellent letter on high altitude mountaineering, may I correct an error in the paper by Moore et $a l^{2}$ in the same issue of this journal? They give the height of Kilimanjaro as 4559 m (14 $960 \mathrm{ft})$. However, the surveyed height of Uhuru Peak on the Kibo summit of Kilimanjaro is $5895 \mathrm{~m}$ or $19340 \mathrm{ft}^{3}$, and believe me, it always felt like it!

N C C SHARP Department of Sports Sciences Brunel University, Borough Road West London TW7 5DU, UK

1 Bailey DM. The ups and downs of high altitude mountaineering. Br $\mathcal{F}$ Sports Med 2001;35:138

2 Moore K, Thompson C, Hayes, R. Diabetes and extreme altitude mountaineering. Br $\mathcal{F}$ Sports Med 2001;35:83.

3 Pugh KT. How high is Kilimanjaro? Tanganyika Notes and Records (fournal of the Tanganyika Society) 1965 ;No 64:144-6.

\section{BOOK REVIEW}

Physical therapist's clinical companion. Springhouse Corporation Staff. (Pp 470; $£ 24.99$.) Oxford: Butterworth-Heinemann, 2001. ISBN 1582550042.

This clinical companion is a reference text for physiotherapists, which attempts to cover all aspects of clinical care as encountered by this clinical group. It has a strong American bias and aims, using a broad based clinical approach, to provide physical therapists with relevant information so that they have a thorough understanding of patients' conditions.

My first impression of this book is that it is compact and well structured with an interesting and diverse contents list. Information is easily accessed from its 15 chapters, which focus mainly on assessment, measurement, and rehabilitation, with a clear description of the contents of each section.

The format is logical and easy to read with an abundance of diagrams and illustrations. However, at some points in the book, the charts appear infinite and interrupt the text for longer than my concentration would allow. The book stimulates the reader to browse through the pages for light reading, but, although the extensive topic content is impressive, the detail is disappointing.

My interest in the book was in the musculoskeletal content which proved lacking. Common disorders encountered in an outpatient setting accounted for one third of one chapter, and the treatment it recommends for low back pain and manual handling manoeuvres would not be in keeping with current clinical effectiveness guidelines in the United Kingdom.

Other areas covering diagnostic tests, signs and symptoms, and outcome measures are covered succinctly for physiotherapists. 